\title{
FEMINISMO E DECOLONIALIDADE NA AMÉRICA LATINA: A LIBERTAÇÃO DA MULHER DOS PAÍSES LATINO-AMERICANOS E SUA CONTRIBUIÇÃO PARA A EFETIVAÇÃO DA SUSTENTABILIDADE
}

\author{
Tatiana Mareto Silva ${ }^{1}$ \\ Aloísio Krohling ${ }^{2}$
}

\begin{abstract}
Resumo:
Este estudo analisou a relação entre a submissão da Natureza e da mulher na América Latina. Partimos da ressignificação da Modernidade e seu deslizamento semântico proposto por Enrique Dussel. Dessa forma, estabelecemos as raízes e fundamentos da submissão da Natureza e da mulher na América Latina colonial e como as diversas colonialidades se reproduziram durante os séculos para gerar uma ideologia que impede ou dificulta a própria sustentabilidade nos países latino-americanos. Concluímos que é necessária uma ruptura com a ideologia eurocêntrica para que a sustentabilidade possa ser atingida na América Latina, requerendo um novo sistema sociopolítico-econômico.
\end{abstract}

Palavras-chave: Modernidade, eurocentrismo, feminismo, sustentabilidade, Natureza.

\section{FEMINISM AND DECOLONIALITY IN LATIN AMERICA: FREEDOM FOR WOMEN OF LATIN AMERICAN COUNTRIES AND ITS CONTRIBUTION TO THE EFFECTIVENESS OF SUSTAINABILITY}

\begin{abstract}
:
This study analyzed the relation between the submission of Nature and women in Latin America. We start from the reframing of Modernity and its semantic slide proposed by Enrique Dussel. In this way, we establish the roots and foundations of the submission of Nature and women in colonial Latin America and how the various colonialities have reproduced over the centuries to generate an ideology that prevents or hinders sustainability in Latin American countries. We conclude that a break with the Eurocentric ideology is necessary for sustainability to be achieved in Latin America, requiring a new socio-political-economic system.
\end{abstract}

Keywords: Modernity, eurocentrism, feminism, sustainability, Nature

\section{INTRODUÇÃO}

\footnotetext{
${ }^{1}$ Doutora em Direitos e Garantias Fundamentais pelo Programa de Pós-Graduação Strictu Sensu em Direito da Faculdade de Direito de Vitória (FDV). Mestre em Políticas Públicas e Processo pela Faculdade de Direito de Campos (UNIFLU/FDC). Pós-graduada em Processo Civil pela Faculdade de Direito de Vitória (FDV). Professora do Curso de Direito do Centro Universitário São Camilo - Espírito Santo.

${ }^{2}$ Pós-doutorado em Filosofia Política na UFRJ e Pós-Doutorado em Ciências Sociais pela PUCSP, Mestrado e Ph.D em Filosofia (Roma, Itália), Mestrado em Sociologia Política, Graduação em filosofia e Ciências Sociais. Professor emérito da UFES. Autor de vários livros e artigos sobre ética, políticas públicas, saúde e direitos humanos.
} 
Em 2015, a Organização das Nações Unidas elaborou a Agenda 2030, um extenso documento que representa o compromisso entre os países do globo por um mundo sustentável. Este documento contém dezessete objetivos voltados para o desenvolvimento sustentável dos países, que enfrentam, resumidamente, os principais desafios para impedir a exaustão do planeta e a extinção da espécie humana.

Dentre estes objetivos, está o número cinco, que determina que o mundo só será sustentável se houver igualdade de gênero. Dessa forma, a questão da desigualdade entre os gêneros e da submissão da mulher se coloca como um obstáculo para a sustentabilidade. No mesmo sentido, podemos considerar que o movimento feminista, cujos objetivos são o de por fim a qualquer espécie de submissão feminina e desigualdade de tratamento entre homens e mulheres, deve ser um aliado do projeto de sustentabilidade estabelecido por qualquer Estado.

Partindo dessas premissas, o presente artigo teve como objetivo principal estudar as teorias feministas conjugadas com a colonialidade dos países latino americanos, buscando relacionar a libertação da mulher com a sustentabilidade latino-americana, voltada para a garantia do direito humano ao meio ambiente ecologicamente equilibrado.

Enfrentamos, assim, uma questão: Quais as relações entre a libertação da mulher e a sustentabilidade, como estabelecem os objetivos de desenvolvimento sustentável da ONU, e como o eurocentrismo colonial contribui para a manutenção da insustentabilidade na América Latina? Para responder a tais questionamentos, utilizamo-nos de pesquisa qualitativa, com de teorias extraídas de referenciais bibliográficos e documentais, e explicativa.

$\mathrm{Na}$ primeira parte do trabalho, analisou-se especificamente as razões pelas quais as Nações Unidas estabeleceram a igualdade entre os gêneros como um objetivo de sustentabilidade. Enfrentou-se, nessa pesquisa, a hipótese de que a universalização do desenvolvimento e do direito fundamental ao meio ambiente equilibrado, ignorando as particularidades culturais e o pluralismo nos países latino-americanos, dificulta ou inviabiliza o desenvolvimento de práticas sustentáveis por estes países.

Ainda, analisou-se também a hipótese que o fim da desigualdade entre gêneros na América Latina, libertando a mulher de sua opressão, é fator de relevo para a garantia do direito fundamental ao meio ambiente ecologicamente equilibrado.

Dessa forma, o presente artigo desenvolveu, utilizando-se o múltiplo dialético de Krohling (2004) como método, uma análise sobre a necessária interpretação transversal e transdisciplinar da sustentabilidade na perspectiva dos países latino-americanos, para que eles 
possam desenvolver políticas e ações sustentáveis conforme suas realidades, e para que possam pautar seu desenvolvimento com base em conceitos e necessidades características de suas regiões e culturas.

Nessa perspectiva, utilizou-se também a crítica de Enrique Leff (2008) sobre a sustentabilidade baseada em uma racionalidade puramente econômica, e a relacionaremos com a colonialidade presente nos países da América Latina para verificar como a dependência cultural obstaculiza que esses países busquem seu melhor desenvolvimento, conjugando a necessidade de uma libertação feminina para a formação de comunidades sustentáveis efetivas.

\section{AMODERNIDADE EUROCÊNTRICA E A PERSISTÊNCIA DA COLONIALIDADE NA AMÉRICA LATINA}

O termo "moderno" é utilizado, frequentemente, com sinônimo de evolução, de sociedade e cultura desenvolvida. Utilizamos a expressão "modernidade" para nos referirmos ao que é bom e deve ser mantido, replicado ou continuado. Em sentido filosófico e histórico, a Modernidade é um longo período de tempo que representa significativas mudanças na organização das coisas, que tem como marco o início do que podemos denominar, conforme Dussel (2005), de história mundial.

A relação entre Modernidade e evolução científica e tecnológica se dá em razão de situarem esse período histórico geralmente com o período do Iluminismo. Como explicou Dussel (2005), a Modernidade é comumente associada ao século das Luzes, em que a Europa representou grande desenvolvimento das artes e das ciências. Essa associação, no entanto, de acordo com os estudos dusselianos, é equivocada, pois a Modernidade teria se iniciado muito antes, durante o período da expansão marítima.

Faremos, a priori, o que Dussel (2005) chama de deslizamento semântico, para ressituar a Europa Moderna dentro de seu contexto histórico adequado. O que é apontado como epicentro da civilização ocidental era, em verdade, um território bárbaro. O ocidente era composto de civilizações "bárbaras", cujo idioma era o Latim, enquanto o oriente era composto das civilizações mais "desenvolvidas", que falavam grego. Assim, Dussel (2005) afirmou que a Europa nunca foi o centro da história mundial, porque, antes da expansão marítima, não havia história mundial. E que nem mesmo o Império Romano foi a base da história europeia, uma vez 
que os impérios muçulmanos e árabes eram mais "evoluídos" e dominavam a Europa prémoderna.

Dussel (2005) aponta uma manipulação ideológica para mascarar a história e apresentar a junção do "mundo cristão", que era latino e grego, contra o "mundo muçulmano", que era turco. Assim, o ocidente passou a ser o império greco-latino, desconsiderando a origem muçulmana do próprio império helenístico (grego).

Temos, assim, dois conceitos de Modernidade. O primeiro representa o abandono do que é imaturo e irracional, em busca de um mundo governado pela razão humana. É a Modernidade como emancipação, que ocorreu apenas no Século XVIII, com o Iluminismo. As fontes iniciais foram a Reforma Protestante e o Renascimento. Dessa forma, França, Inglaterra e Itália seriam os expoentes da Modernidade, o que é contestado por Dussel (2005).

O segundo conceito de Modernidade, evidenciado na obra dusseliana, afirma que a história mundial se iniciou com a expansão marítima europeia, tendo, assim, Portugal e Espanha como expoentes. Dessa forma, uma primeira etapa da Modernidade instaura o mercantilismo a nível mundial e, a partir de 1492, a Europa se torna centro, instituindo todas as demais culturas como periféricas.

Dussel (2005) afirmou que o Eurocentrismo decorre de uma confusão comum entre a universalidade abstrata e a mundialidade concreta. A Modernidade iniciou-se com o ego conquiro antes do ego cogito do Iluminismo, ou seja, a Europa utilizou-se da força, do apagamento e da aniquilação para superar outras culturas, não da razão. A América Latina sofreu os efeitos da Modernidade antes da América do Norte, conquistada e explorada pela expansão hispano-ibérica.

A importância em se ressignificar a Modernidade reside na necessidade de se superar o mito que apaga ou esconde seu histórico de violência. Assim, para Dussel (2005), superar a Modernidade representa negar a negação do mito moderno e reconhecer que a colonização da América Latina não significou civilização nem o "salvamento" das pessoas que aqui habitavam, mas a aniquilação de culturas e povos que foram os originais habitantes das regiões colonizadas.

A cultura latino-americana foi encoberta pelo europeu que aqui chegou. $\mathrm{O}$ discurso civilizatório escondeu a sanha exploratória dos colonizadores, que tinham como objetivo extrair o máximo das terras recém conquistadas para alimentar o comércio mundial que se estabelecia.

Dussel (2005) propõe uma transcendência dessa Modernidade, ou seja, o reconhecimento 
do caráter racional da Modernidade mas como projeto de libertação mundial. A Modernidade com alteridade e solidariedade é denominada Transmodernidade e supera o mito moderno do europeu evoluído e civilizado e dos ameríndios incivilizados que foram salvos e resgatados da barbárie.

A superação do mito da Modernidade é fundamental para a compreensão das características da colonização europeia na América Latina, o que se torna essencial para a superação dessa irracionalidade mencionada por Dussel (1993).

Nesse mesmo caminho, o eurocentrismo deve ser compreendido e superado em busca da libertação da América Latina. Dussel (1993) explicou que a falácia da Europa como centro representou uma manipulação de fatos e contextos que ocultou parte da história e a recontou, de uma narrativa que permitisse à Europa a sua centralidade. Assim, a história eurocêntrica caminha do oriente para o ocidente, permitindo que a Ásia seja considerada desenvolvida, bem como parte da África. O sul do continente africano e a América Latina são excluídos desta narrativa por não poderem ser nela localizados geopoliticamente.

Quijano (2014) explica o Eurocentrismo como um projeto cognoscente, que representa a racionalidade europeia, o modo de produção capitalista e, ainda, contempla todo o conjunto dos que são educados sob esse sistema. Esse projeto foi iniciado com a Modernidade desde a expansão marítima, com a colonização, que precisou estabelecer novas formas de relacionamento entre os seres humanos e a Natureza e a naturalização de determinadas estruturas e modos de pensar e ser, para que pudessem ser compreendidas como inevitáveis e corretas.

Trataremos, a seguir, de como esse projeto eurocêntrico decorrente da colonização dos países da América Latina produziu modos específicos de exploração e de submissão, que se perpetuaram mesmo depois da independência política das antigas colônias, em razão do enraizamento de valores e processos que foram naturalizados e impostos aos povos nativos das regiões colonizadas.

\section{A COLONIZAÇÃO DA AMÉRICA LATINA E A EXPLORAÇÃO DA NATUREZA}

Para Quijano (2014), o poder é uma teia de relações sociais que representam exploração e dominação, garantindo o controle de cinco elementos: 1) trabalho e os produtos do trabalho; 2) a Natureza e os recursos naturais, matérias-primas para a atividade humana; 3) o sexo e a reprodução das espécies; 4) a subjetividade, incluindo o conhecimento como produto intersubjetivo; e 5) a autoridade, em particular os seus instrumentos de coerção. 
Nessa perspectiva, a Modernidade eurocêntrica representaria, em qualquer variante de estudo, um "postulado historicamente impossível" (QUIJANO, 2014, p. 291), que seria a predeterminação ahistórica das características das relações sociais de poder. Ou seja, as relações seriam determinadas antes mesmo de sua história, pressupondo que já fossem definidas previamente.

O estabelecimento desses padrões como normais e naturais para todos e todas definem o Eurocentrismo e compõem o projeto que molda o conhecimento durante o período da colonização, pretendendo que os povos colonizados renegassem seus modos de vida - que eram incorretos, subdesenvolvidos e precários - em prol do modo de vida europeu - que era racionalmente adequado, desenvolvido e que lhes proporcionaria vida boa.

Considerando que a expansão marítima europeia instaurou o mercantilismo mundial, também houve a mundialização do próprio modelo capitalista, emergente na Europa, e que precisava ser alimentado pelas novas regiões "descobertas" por espanhóis e portugueses. Essas regiões eram fartas em elementos naturais que a Europa não possuía, apresentando-se como uma rica fonte de recursos para abastecer o sistema mercantilista.

Em um primeiro momento, a Natureza era concebida como um espaço selvagem e incontrolável, pelo europeu colonizador, onde se proliferavam doenças e os mais variados perigos. O papel do ser humano, portanto, era domesticar a Natureza para transformá-la em um lugar agradável e seguro. Essa visão da Natureza era comum na Europa e se reproduziu nas colônias da América Latina. Apesar da admiração declarada pelas paisagens, era necessário controlar a força incontrolável da Natureza. Essa proposta visava civilizar a Natureza para que ela pudesse oferecer, ao ser humano, frutos e recursos (GUDYNAS, 1999).

A concepção da Natureza como fonte de recursos foi se estabelecendo, dentro de uma perspectiva utilitarista, a medida em que ela era "decifrada" pelo ser humano. A descoberta de minerais e vegetais que poderiam ser extraídos e utilizados passou a conduzir as relações entre seres humanos e Natureza, em uma crença de que os "recursos naturais" eram infinitos e nunca se esgotariam. Walsh (2007) estabeleceu que a colonização da América Latina produziu uma colonialidade da Natureza que se funda na divisão cartesiana entre sociedade (construída) e Natureza (natural). Assim, a relação entre Natureza e os povos ameríndios foi mitificada e ridicularizada, transformada em lenda e folclore, não identificada como processo histórico e substituída pelo processo racional da Modernidade. 
A colonialidade da Natureza nega as relações entre a Pacha Mama e o humano. Nega, inclusive, que o ser humano seja parte da Natureza, que é coisificada e transformada em recurso mineral, vegetal ou animal para ser consumido, utilizado e modificado conforme o interesse humano, em uma perspectiva meramente utilitarista.

Esse processo estabeleceu uma ruptura total com o modo de ser e de se relacionar dos povos ameríndios com a Natureza, desqualificando-os e reenquadrando-os dentro do modelo europeu. O processo de colonização do saber (QUIJANO, 2014 e WALSH, 2007) tratou de eliminar as formas ditas subdesenvolvidas e primitivas de relações entre humanos e o restante do planeta para substituí-las pelo modelo de exploração que alimentaria o sistema desenvolvimentista europeu.

Gudynas (1999) explicou que a chegada de espanhóis e portugueses na América Latina deu início a uma estratégia de apropriação e exploração da Natureza, com o desenvolvimento de uma agricultura altamente nociva e espoliativa da terra, bem como a extração desenfreada de recursos minerais, tudo isso baseado na mão de obra escrava. A crença de uma Natureza infinita sustentava a justificativa de que os recursos naturais deveriam ser explorados livremente pelos seres humanos.

Os modelos científicos da Modernidade também contribuíram para legitimar a exploração imoderada das terras colonizadas, pois representaram a ruptura do modelo prémoderno de concepção da Natureza como um organismo. O afastamento do ser humano da Natureza, e sua elevação como única criatura racional do planeta, se uniu aos modelos científicos da Modernidade para reduzir a Natureza à categoria de recurso, "terra", bem para exploração e uso humano.

A visão antropocêntrica que se acentuou significativamente na Modernidade europeia é, portanto, também responsável pela cultura de abuso da Natureza. Em conjunto com as propostas utilitaristas e positivistas de progresso ilimitado como a melhor forma de desenvolvimento de uma sociedade, o modelo Eurocêntrico produziu, como estabeleceu Gudynas (1999), uma ideologia do progresso que definiu as formas de relação entre seres humanos e Natureza, a partir de então, e que produziram eco na América Latina em razão da colonização.

Os países da América Latina adotaram, como padrão de desenvolvimento, o modelo europeu, que também foi implantado na América do Norte, ressalvando-se as diferenças entre modelos de colonização. Nos estudos de Sunkel (1980) e Gligo (2006), compreendemos que esse modelo de desenvolvimento como crescimento universaliza o impossível, estabelece modelos 
únicos que são considerados os adequados, e que homogeneiza padrões que desconsideram as diferenças de industrialização e estrutura de cada país.

Porém, a colonização também afetou o conhecimento produzido na América Latina (e para a América Latina), levando com que as ciências também se submetessem aos modelos europeus. O sistema de colonização violento e espoliativo, que foi obscurecido pelo mito da Modernidade (DUSSEL, 2005), também violou a forma como os países da América Latina continuaram a se desenvolver mesmo depois de suas independências políticas, moldados pelos padrões europeus que não representavam a realidade desses países - nem antes, nem depois da colonização.

Com isso, a Modernidade eurocêntrica impôs a perpetuação de uma cultura imposta de cima para baixo, de fora para dentro, que ecoou no modelo considerado ideal para um Estado se desenvolver, no modelo considerado ideal para as pessoas viverem bem, no modelo ideal de relação entre seres humanos e Natureza, independentemente das características específicas de cada região ou cultura. A diversidade foi ignorada e indesejada, preterida em prol da uniformização e universalização do conhecimento e do desenvolvimento.

Essa ideologia, apontada por Gudynas (1999), representa, para Leff (2008) o principal problema da sustentabilidade planetária. Explicamos: os projetos transnacionais (globais) que buscam frear e impedir a degradação ambiental, que começaram a ser idealizados em 1972, com a Conferência de Estocolmo, são projetos universais que não dão o necessário peso à diversidade de culturas e formas de interação das comunidades com o meio ambiente, nem consideram as diferenças de industrialização e vivência de cada comunidade.

O modelo de desenvolvimento como crescimento, que Sunkel (1980) afirmou ser "perigoso" por se basear em premissas incorretas - como a infinitude dos recursos naturais, conduziu a crises ambientais severas que, em meados do Século XX, passaram a preocupar toda a comunidade global. Com isso, as Nações Unidas intervieram na questão ambiental, havendo o reconhecimento expresso do direito humano ao meio ambiente equilibrado na Declaração de Estocolmo (1972).

Leff (2008) defendeu que, apesar de o mundo passar a enxergar a questão ambiental como essencial para a sobrevivência humana, ela ainda estava fundada em raízes antropocêntricas e economicistas. Ou seja, os projetos sustentáveis se baseavam nas mesmas ideologias desenvolvimentistas que originaram a crise ambiental, não sendo, dessa forma, sustentáveis. Relacionamos a questão ambiental, especificamente nos países da América Latina, 
com a colonialidade e o mito da Modernidade que foram responsáveis pela forma de exploração da Natureza nas regiões colonizadas.

\section{A COLONIZAÇÃo dA AMÉRICA LATINA E A DUPLA OPRESSÃO DA MULHER AMERÍNDIA: A COLONIALIDADE DO MACHISMO}

As desigualdades permanentes e resistentes no mundo colocam diversos grupos em situação de constante violação de seus direitos humanos. Esses grupos, marginalizados e invisibilizados, são excluídos dos tradicionais espaços públicos, sejam eles políticos ou econômicos, e não participam ativa e efetivamente da construção da sociedade. Incluímos as mulheres como grupo historicamente invisibilizado, considerando a segregação delas aos espaços privados (ARENDT, 2007) em razão da estigmatização dos papéis femininos determinados pela sociedade patriarcal.

O gênero mulher é socialmente construído para o sexo feminino (SCOTT, 1995). A sociedade patriarcal machista relegou, às mulheres, papeis socialmente invisíveis, como os cuidados com o lar e a maternidade. As diferenças biológicas entre sexos serviram de fundamento (equivocado) para o confinamento das mulheres em suas casas, impedindo-se que elas pudessem participar ativamente da vida pública em razão de "atributos naturais" do gênero (BEAUVOIR, 2009; OKIN, 2008).

Nesse sentido, as mulheres foram excluídas da participação democrática na construção das sociedades ocidentais, modernas ou pós-modernas. O produto que temos hoje é uma sociedade ocidental cunhada na desigualdade entre gêneros, predominantemente masculina, onde todos os espaços públicos foram construídos por homens e para homens. A predominância cultural do masculino no discurso, no legislado, é resultado de séculos de invisibilização histórica das mulheres.

Essa sociedade masculina também é uma sociedade opressora para outros grupos vulneráveis e depredadoras para a Natureza. Da origem da desigualdade entre gêneros, também nasce a justificação da exploração da Natureza, haja vista que o antropocentrismo é fonte de ambas. Explicamos: a sociedade contemporânea é derivada da moderna, fundada sobre o racionalismo iluminista que elevou o homem (masculino) ao nível de centro do Universo. No racionalismo, abandonou-se o cosmo em prol de uma supervalorização do homem, submetendo todas as demais coisas e seres viventes à sua dominação. 
Dessa forma, tanto as mulheres (o feminino) quanto a Natureza (o ambiente) foram submetidas à exploração masculina pela sociedade antropocêntrica moderna, cujos fundamentos permanecem até o Século XXI. Somado a esse cenário, está a exploração dos países periféricos, denominados também como "do sul", que ocupam a parte subdesenvolvida economicamente do planeta, em razão de séculos de colonização europeia e norte-americana.

A América Latina, dessa forma, sofre com o estabelecimento de padrões sociais antropocêntricos, eurocêntricos e androcêntricos. Podemos estabelecer que exploração dos países latino-americanos sustenta-se em três pilares: i) a exploração da Natureza, com o extrativismo permanente, a escravização e submissão das comunidades rurais pela indústria internacional; ii) a colonização cultural que impõe padrões europeizados para o pensamento e o modo de viver como se fossem valores absolutos e universais; iii) a dupla subjugação da mulher latinoamericana, que foi submetida pelos homens latinos e, posteriormente, pelos homens colonizadores.

Discorremos sobre a denominada dupla opressão sofrida pela mulher latino-americana, que está respaldada na colonialidade do ser, apontada por Walsh (2007). Como o modelo de sociedade patricarcal, ocidental, estava estabelecido na Europa, no período da expansão marítima, ele foi trazido para as regiões colonizadas. A mulher, subjugada aos espaços privados na Europa, não tinha direito de voz nem participação social. O colonizador também considerava os povos ameríndios como bárbaros, inferiores a ponto de não serem capazes de ascender ao nível de civilização do europeu. Nessa perspectiva, Walsh (2007) explicou que, aos habitantes das regiões colonizadas, era esperado que realizassem apenas alguns papeis sociais, subalternos e inferiorizados.

Dessa forma, a mulher colonizada era duplamente oprimida, primeiro por ser mulher, segundo por ser uma habitante incivilizada de uma região subdesenvolvida. O colonizador tratou diretamente com o homem nativo, nunca com a mulher. Sua condição feminina a colocava em patamar de inferioridade até mesmo dentro de sua própria cultura, era a visão dos europeus em relação às ameríndias.

Essa condição de dupla opressão perdura até os dias atuais. As mulheres latinoamericanas estão mais vulneráveis à exploração sexual por estrangeiros e a Natureza latinoamericana está vulnerável por ainda manter biodiversidade exclusiva, de interesse dos países mais industrializados, no norte. Ainda, as mulheres latino-americanas, como referencial de mão 
de obra mal paga - mulheres sempre exerceram os trabalhos mais mal remunerados e não pagos estão mais expostas, também, a serem exploradas em situações análogas à escravidão.

Como explicou Walsh (2007), as ciências dos países americanos consolidaram-se como uma reprodução das ciências liberais europeias da modernidade, que tratou de desqualificar e desconsiderar a produção do conhecimento, nos países colonizados. O europeu considerava a sua ciência como universal e, consequentemente, única válida para todo o mundo. A assimilação das culturas dos países colonizados deu-se também pelo seu apagamento - as universidades reproduziam a ciência cartesiana moderna e o conhecimento europeu era o paradigma a ser reproduzido e seguido.

Nesse sentido, Walsh (2007) compreende que não é possível simplesmente abrir as portas do conhecimento para novos paradigmas, mas reconsiderar os próprios espaços de produção epistemológica para fora das academias, além dos fundamentos do conhecimento que se chama "certo" ou qualificado (que é hegemônico). Walsh (2007) não entende que o conhecimento hegemônico deva ser desconsiderado, como foi feito com o conhecimento da colônia, mas que deva ser exposta a sua faceta colonizadora e imperialista, em que uma universalização foi considerada de forma a legitimar a colonização, a violência do colonizador e a eliminação da cultura local.

Walsh (2007) estabelece quatro dimensões de colonialidade que interferem nas relações entre o centro e a periferia: (a) a colonialidade do poder, com padrões de raça, classe e relações de trabalho, que sustentaram a imposição do branco europeu sobre o índio e o negro; (b) a colonialidade do saber, que representa a legitimação da ciência moderna europeia como única forma válida de produção de conhecimento, desqualificando a cultura indígena que não era considerada conhecimento; (c) a colonialidade do ser, em que uma categoria de pessoas se sobrepõe a outras, criando classes de indivíduos mais valiosos do que outros, que exercem um controle das subjetividades; e (d) a colonialidade da natureza, em que a racionalidade lógica cartesiana buscou eliminar a forma de relação entre os nativos das Américas e a natureza.

Por colonialidade do poder, temos a legitimação e a consolidação do sistema de classes e raça de divisão do trabalho. Os povos colonizados se tornaram escravos ou, mesmo livres, assumiram os papéis mais subalternos da estratificação social (QUIJANO, 2005). Os índios nativos passaram a exercer as funções que os brancos europeus não nobres exerciam, antes, elevando socialmente os homens brancos e rebaixando os homens mestiços e dos povos nativos. Quijano (2005, p. 119) explicou que 
Desde o século XVIII, na América hispânica muito dos mestiços de espanhóis ou mulheres índias, já um estrato social extenso e importante na sociedade colonial, começaram a ocupar os mesmos ofícios e atividades que exerciam os ibéricos que não eram nobres. Em menor medida ou sobretudo em atividades de serviço ou que requeriam talentos ou habilidades especiais (música, por exemplo), também os mais "abrancados" entre os mestiços de mulheres negras e ibéricos (espanhóis ou portugueses), mas demoraram a ver legitimados seus novos papéis, já que suas mães eram escravas. A distribuição racista do trabalho no interior do capitalismo colonial/moderno manteve-se ao longo de todo o período colonial.

As classes de trabalhos eram relacionadas às raças e cada tipo de trabalho também representava uma diferente forma de controle de determinados grupos. Para Walsh (2007), a Modernidade eurocêntrica advinda com a expansão marítima e a colonização dos povos ameríndios instituiu um novo sistema de classificação, o racial.

Por colonialidade do saber, entendemos a dominação hegemônica do conhecimento, que segrega determinadas culturas e tipos de saberes que não aqueles forjados no eurocentrismo. Para Walsh (2007), a colonialidade do saber se deu com a imposição do eurocentrismo como única forma de conhecer o mundo. Baquero et al (2015) afirmaram que, durante o colonialismo, a desqualificação do saber dos povos primitivos se dava simplesmente pela cor da pele mas que, com a independência das colônias, a negação do valor da produção intelectual desses povos adotou contornos mais sutis, debaixo de um mito de uma ciência supostamente neutra, universal e objetiva.

Repetimos que não se trata de desconsiderar o valor da ciência da Modernidade eurocêntrica para a humanidade, e o avanço tecnológico por ela gerado. A colonialidade do saber reside na compreensão de que essa ciência Moderna europeia foi imposta como única forma válida de produção do conhecimento, principalmente após o Iluminismo, se considerarmos que o eurocentrismo já se manifestava fortemente nas colônias latino-americanas e africanas. O conhecimento dos povos ameríndios foi ignorado e considerado primitivo, inferior ao conhecimento europeu, devendo ser substituído por este último.

Nesse sentido, o saber eurocêntrico possuiu força de "impor sua narrativa histórica como o conhecimento objetivo, científico e universal" (LANDER, 2000, p. 12), e essa força foi sustentada por condições específicas, decorrentes do colonialismo. Ou seja, o colonialismo americano não representa tão somente a organização colonial do planeta, mas, ainda, a 
substituição dos saberes, da linguagem e da memória tradicionais de povos colonizados pela do colonizador.

Por colonialidade do ser, temos a influência direta do Iluminismo francês em seu sujeito universal transcendental, deslocado e sem historicidade. Como afirmou Gómez-Quintero (2010, p. 88), "a filosofia moderna não pensou o sujeito em sua realidade imediata, ao contrário, tachou de primitivas e selvagens algumas das formas sociais das quais fazia parte”. Esses sujeitos, inferiores, não eram capazes de ascender ao mesmo nível do sujeito europeu, universalizado e, portanto, serviam apenas para determinados papeis sociais.

O povo colonizado assumiu uma face oposta à do colonizador que, ao invés de reconhecer suas diferenças e sua outridade por meio do diálogo e da interpelação, buscou a assimilação. Maldonado-Torres (2007) entendeu que a necessidade de se estabelecer a dimensão da colonialidade do ser refere-se à importância de se compreender a relação entre colonizador e colonizado pelas experiências vividas, não apenas pela questão intelectual. Nesse sentido, a desumanização do colonizado, praticada pelo colonizador, representou a inferiorização justificada desse sujeito diferente e incapaz de atingir os padrões ideais da Modernidade eurocêntrica.

Nesse contexto, temos os índios colonizados e os negros escravizados. A questão da colonialidade do ser, transportada para a discussão feminista, apresenta um agravante, que é a distinção entre homens e mulheres antes da distinção entre brancos e não-brancos, colocando a mulher em uma situação de subalternidade ampliada, pois o sujeito mulher colonizada era inferior ao sujeito homem colonizado.

Assim, a colonização da América Latina colocou as mulheres locais em uma situação de complexa submissão, pois as três dimensões trazidas por Walsh (2007) se abateram sobre as mulheres dentro de um contexto já estabelecido de inferioridade feminina, na Europa. Ou seja, os valores europeus trazidos e impostos, tanto em relação ao poder, ao conhecimento e ao ser, já colocavam a mulher em posição de sulbaternidade, como exposto anteriormente. A mulher latino-americana, portanto, passou a ser uma mulher subalterna dentro de um contexto de indivíduos subalternos.

Quando os homens brancos europeus colonizaram as Américas, eles transpuseram sua cultura de dominação do masculino sobre o feminino e todo diálogo ou tentativa de diálogo se estabeleceu com outros homens, colonizados. As mulheres foram excluídas duplamente pelo 
homem europeu e, com o tempo e o apagamento da cultura local (latino-americana), os próprios colonizados passaram a reproduzir o machismo patriarcal da Europa como modelo social.

Lugones (2014) considerou que a colonização da América Latina evidenciou a dicotomia mais característica da Modernidade, a de humanos e não-humanos. Os colonizadores eram seres humanos, os colonizados eram povos primitivos, coisas, não humanos - houve, dessa forma, uma reificação do colonizado e, consequentemente, a supressão de qualquer direito ou valor humano que lhe fosse possível atribuir. Os colonizadores eram homens e mulheres, os colonizados não ascendiam a essas categorias, pois não eram humanos.

Transportando essa compreensão para o feminismo, podemos apreender que as teorias feministas produzidas pelo centro (Europa-Estados Unidos) são desconectadas da realidade latino-americana na universalização do sujeito europeu como padrão adequado a ser seguido e reproduzido. A própria história da luta de mulheres por conquistas nos espaços públicos é uma história europeia, decorrente do modelo de sociedade machista e misógino implantado na Europa, perpetuado durante os séculos.

Não havia que se falar de um feminismo latino-americano, antes da Modernidade iniciada em 1492, porque a) a situação das mulheres ameríndias era diversa da situação das mulheres europeias, em se considerando o modelo de sociedade de cada região, e b) a história das Américas colonizadas foi apagada, dizimada e deslegitimada pelo colonizador, fazendo parecer que, até a chegada de espanhóis e portugueses na América Latina, tudo que havia naquela região era "selvagem" e sem valor como cultura.

\section{A RELAÇÃo ENTRE O FEMININO E A NATUREZA E A PROPOSTA DA SUSTENTABILIDADE: DISCUSSÕES RELEVANTES}

A relação entre a opressão da mulher e a depredação da Natureza é entendida por duas correntes teóricas, sendo uma mais essencialista, que conecta a mulher à Natureza por suas características femininas (o princípio feminino) e, outra, socialmente construída, em que mulher e Natureza são inferiorizadas pelo antropocentrismo androcêntrico europeu, que, ao elevar o homem (masculino) à categoria de ser vivo detentor de mais direitos do que os demais, legitimou a coisificação do feminino e do ambiente. De qualquer forma, os temas estão conectados a ponto de tornar relevante quaisquer estudos no sentido de libertar ambas - tanto mulher quanto Natureza - da opressão masculina para que, assim, se possibilite uma efetiva sustentabilidade planetária. 
Justificamos, então, a relação entre sustentabilidade e a igualdade entre gêneros a partir da fonte da opressão de ambas ser o modelo social estabelecido até hoje. Enquanto a relação do ser humano masculino for de exploração e submissão, seja do feminino, seja do ambiente, o planeta sofrerá as consequências da sanha conquistadora do homem. A ruptura com o antropocentrismo machista representaria uma convergência entre o respeito à mulher e o respeito à Natureza como seres de direitos - o que deverá conduzir a Humanidade à construção de novas relações mais saudáveis e sustentáveis com o ambiente.

Existe uma questão feminina, da inferioridade do feminino em relação ao masculino, de encobrimento da mulher e seu confinamento aos espaços privados, onde sofreu, historicamente, violência. Como visto neste estudo, durante muitos séculos, na história da humanidade, a mulher vem sendo subalternizada, inferiorizada e violada em sua dignidade, e que esse modelo de desigualdade e inferiorização dos gêneros chegou de forma mais enfática na América Latina por meio do eurocentrismo hegemônico.

A Europa possuía um modelo de sociedade em que as mulheres não possuíam os mesmos direitos dos homens, e isso representou a segregação do feminino dos espaços públicos, a impossibilidade da mulher em contribuir para a construção da sociedade, a violência patriarcal do masculino sobre o feminino e a desqualificação de tudo que pudesse ser considerado feminino como sinônimo de fraqueza e debilidade.

Durante a colonização, a mulher latino-americana foi demonizada, mitificada e desqualificada pela imposição do modo de vida europeu aos povos ameríndios. Nesse sentido, a questão feminina - da inferiorização do gênero mulher, do sexo feminino, é também uma questão de colonialidade, que imbrica por suas esferas já analisadas.

E existe a questão ecológica, que representa a degradação da Natureza pelo ser humano, de forma a colocar em risco a sobrevivência da própria raça humana no planeta. Essa questão, que se agrava na América Latina, a priori pode apresentar-se como dissociada da questão feminina, uma vez que, ao menos aparentemente, a inferiorização da mulher não possui relação direta com a exploração da Natureza. Em uma análise meramente disciplinar e fragmentada da história, dificilmente seria possível relacionar uma opressão com outra.

Porém, por meio da análise transversal e a conjugação dos saberes, de acordo com o método da racionalidade ambienta, com a captação da historicidade dessas questões, podemos entender que a opressão feminina e a exploração da Natureza decorrem de modelos 
epistemológicos comuns, quais sejam, o androcentrismo europeu, que é machista, patriarcal e antropocêntrico.

A relação entre feminino e Natureza pode ser analisada tendo como fio condutor o feminismo ecológico ou ecofeminismo. Considerando o feminismo como um movimento plural, que não foca em um sujeito universal, mas nas mulheres com suas individualidades e historicidades, existem também as facetas do feminismo que conjuga a luta pela igualdade entre os gêneros e o fim da exploração descontrolada da Natureza.

O feminismo europeu e estadunidense é hegemônico e eurocêntrico. A luta das mulheres europeias, sejam elas as francesas que despontaram no período da revolução francesa, aproveitando a abertura gerada pela revolução (MIYAMOTO; KROHLING, 2013), sejam elas inglesas como Astell e Wollstonecraft, representou um momento muito importante para a história dos direitos femininos, porém os ideais defendidos por essas mulheres eram liberais.

O liberalismo europeu, que foi reproduzido nas colônias norte americanas que originaram os Estados Unidos da América, à época da Revolução Francesa, da Iluminura e do Renascimento, defendia a bandeira da liberdade e da igualdade acima de tudo. A Europa não vivenciou a escravidão e a divisão por classes e raça em seu território, ela se expandiu para os países do norte, periféricos, e os colonizou. Foi nas colônias que os europeus escravizaram e exploraram pessoas, consideradas diferentes e incivilizadas, que sofreram a aniquilação e o encobrimento de suas culturas.

O feminismo europeu não se ocupou diretamente da pluralidade do sujeito mulher porque desconsiderava essa realidade. A mulher negra, a mulher indígena, a mulher escravizada, a mulher duplamente subalternizada por sua condição feminina e por sua condição de colonizada, não fazia parte do estudo e do objeto do feminismo europeu que despontou na primeira onda. As mulheres europeias lutavam por direitos de liberdade e igualdade, como o direito de votar, de trabalhar e de ocupar cargos políticos. Pleiteavam direitos básicos como o de estudar e frequentar universidades, o divórcio, o controle de seus próprios corpos.

A questão de classe e de raça não era objeto do feminismo europeu, bem como a questão de opressões transversais, como a exploração da Natureza. Em uma percepção histórica do feminismo europeu como movimento, seja ele a luta isolada das primeiras mulheres que se insurgiram contra o sistema patriarcal que as invisibilizava, seja a organização de grupos que reuniram para lutar por direitos negados, como as sufragistas, o pleito das feministas europeias não considerava a possibilidade ou a existência de um sujeito mulher plural, nem se pautou em 
uma opressão de várias camadas, em que diferentes mulheres estariam em condições de maior violação de direitos do que outras.

Nenhuma dessas constatações diminui a importância do movimento feminista europeu ou do feminismo estadunidense para a história da luta pelos direitos das mulheres. Porém, nos leva a compreender que tais movimentos se mostraram possivelmente insuficientes para atender a todas as demandas de todas as mulheres, uma vez que a) existem diversos sujeitos mulheres, e b) a opressão e a violência sofrida por esses múltiplos sujeitos se entrelaça a outras opressões vivenciadas em razão da classe social, da raça, da sexualidade, da colonialidade.

Ainda assim, o termo feminismo ecológico foi tratado pela primeira vez por uma francesa, Françoise D’Eaubonne, citada por Warren (2004), para referir-se às relações históricas, empíricas, éticas, epistemológicas, entre outras, entre mulheres e Natureza. Podemos dizer que o feminismo ecológico, ou ecofeminismo, é uma das muitas vertentes do feminismo que analisa as relações paralelas entre a dominação das mulheres e da Natureza por um sistema único de opressão (WARREN, 2004).

Ruether (1996) explicou que, em um nível de análise, "o ecofeminismo se funda na intuição básica de que na cultura ocidental - e nas culturas patriarcais de modo geral - há uma conexão fundamental entre a dominação das mulheres e a dominação da natureza". Já em outro nível de análise, em uma dimensão socio-econômica, o feminismo ecológico questiona os padrões culturais e simbólicos de inferiorização tanto das mulheres quanto da Natureza, dentro de uma superestrutura ideológica que naturalizou a opressão e a exploração de ambas em uma cosmovisão patriarcal (RUETHER, 1996).

Para Warren (2004), o feminismo ecológico é feminista porque utiliza, em suas análises, a lente do gênero. Nesse sentido, o ecofeminismo tem um "duplo compromisso de reconhecer e eliminar os prejuízos causados pelo gênero masculino, onde e quando se deem, e com o desenvolvimento de práticas, políticas e teorias que não contenham desigualdade de gênero" (WARREN, 2004, p. 63). O feminismo ecológico também é ecologista porque compreende que os seres humanos são seres ecológicos, que fazem parte de uma rede sistêmica, e reconhece a necessidade de uma dimensão ecológica a toda e qualquer categoria de análise filosófica.

Nessa perspectiva, "segundo o feminismo ecológico, qualquer feminismo que não se nutra do conhecimento ecologista, especialmente das mulheres e da Natureza, e qualquer filosofia ambiental que não se nutra das aproximações do ecofeminismo, é simplesmente 
inadequado" (WARREN, 2004, p. 64). Esse movimento ecologista feminista é também plural e multicultural, a ponto de Warren (2004) afirmar que não existe apenas um ecofeminismo bem como não existe apenas uma filosofia ecofeminista. A multiplicidade de matizes analisadas e questionadas pelo feminismo ecológico faz com que existam mais de um movimento dentro do movimento que já é uma vertente de outro movimento.

Fazendo uma análise mais aprofundada do feminismo ecológico, enfatizamos a existência de duas vertentes mais comuns - uma essencialista, uma crítica. A vertente essencialista, ressalta as diferenças biológicas entre feminino e masculino e aproxima a mulher da Natureza, justificando, assim, a conexão entre as opressões e as lutas (SORJ, 1992). A vertente crítica não se fundamenta na proximidade biológica entre mulheres e Natureza, mas na questão cultural - a sociedade patriarcal androcêntrica que oprime a mulher e explora a Natureza teria a mesma base epistemológica.

A crítica ao feminismo ecológico também pode ser representada por vertentes do feminismo que negam a ideia de um ecofeminismo, ou seja, de uma aproximação entre as lutas feministas e ecológicas. Não consideramos a ética produzida pelo feminismo ecológico como modelo para a construção da epistemologia ambiental e, consequentemente, para a contribuição na construção de modelos de sustentabilidade mais eficazes sem considerar que esse movimento também deve ser sempre submetido à autocrítica por seus próprios fundamentos.

Os fundamentos éticos de uma filosofia feminista ecológica que permita uma análise transversal das questões envolvendo a opressão da mulher na sociedade moderna europeia, a desigualdade entre os gêneros reproduzida na América Latina pelo eurocentrismo hegemônico, a exploração da Natureza dentro do sistema econômico capitalista, a degradação ambiental e a precarização das condições de vida dos grupos minoritários e excluídos, principalmente nos países periféricos, nos quais se incluem os latino-americanos.

A construção de um modelo epistemológico para a filosofia ecofeminista que considere o entrelaçamento de todas essas questões, sem que uma se sobreponha à outra, sem que se tente, com isso, uma unificação do saber em outra área de conhecimento, adequa-se à dialética da racionalidade ambiental e contribui para uma cosmovisão que transcenda a própria ideia homemnatureza, para a percepção ser humano-natureza.

A discussão do feminismo ecológico se entrelaça com o feminismo descolonial, também na hipótese transversal de análise entre a colonialidade do ser, tratando o feminino colonizado como o diferente, e a colonialidade da Natureza. As dimensões da colonização, que perduram até 
a atualidade, serão analisadas de forma transdisciplinar, com objetivo de verificar a necessidade e a relevância da libertação epistemológica dos movimentos feminista e ecologista para a eficácia da sustentabilidade na América Latina.

\section{CONCLUSÕES}

O estudo, que se desenvolveu pela racionalidade ambiental de Enrique Leff (2008), um método dialético de estudo para a proposta da nova epistemologia ambiental por ele sugerida, obteve os seguintes resultados na verificação das hipóteses e discussão da problemática:

A Modernidade, mesmo que comumente relacionada com o período do Iluminismo europeu, teria se iniciado bem antes, no Século XV, durante a expansão marítima que projetou a Europa para a conquista de territórios além-mar e que teria instaurado a história mundial, ao colocar a Europa no centro do planeta e constituir as demais regiões como periféricas.

A compreensão da Modernidade como um projeto de conquista, dominação e submissão representa a negação de um mito - o mito da Modernidade que teria sido benéfica para os países colonizados e fundamental para a evolução mundial. A negação deste mito não significa o abandono da razão nem da contribuição científica do período, mas tão somente a reflexão sobre a violência produzida pela Europa, que massacrou, eliminou e submeteu as culturas dos países colonizados sob o argumento de que eram culturas inferiores e incivilizadas.

A violência da Modernidade também representou uma ideologização do que é desenvolvimento, em uma universalização dos valores socioculturais-econômicos europeus como se fossem os únicos adequados à humanidade. Essa universalização desconsiderou e ignorou a pluralidade e a diversidade das culturas dos países colonizados e é denominada eurocentrismo. Em razão do eurocentrismo, as formas como os povos ameríndios se relacionavam com a Natureza foram desqualificadas e mitificadas, sendo substituídas pelo modelo científico moderno, em que a Natureza era um objeto, e pelo modelo capitalista de consumo, em que a Natureza era um recurso.

Da mesma forma, as formas de relações entre homens e mulheres dos povos colonizados foram substituídas pelo modelo do patriarcado europeu. Os colonizadores submeteram as mulheres colonizadas duplamente, tanto pelo sistema colonial (eram incivilizadas, portanto bárbaras) quanto pelo sistema patriarcal (eram mulheres, portanto inferiores). Essa dupla submissão da mulher ameríndia reflete em uma desigualdade de gêneros agravada nos países colonizados, até hoje, e que nem mesmo foi objeto de estudo dos primeiros movimentos 
feministas, na Europa e nos Estados Unidos. O feminismo branco europeu desconsiderou a realidade das mulheres colonizadas e deixou de refletir, portanto, sobre a relação entre o machismo patriarcal do colonizador e a submissão da Natureza.

A relação entre a submissão da Natureza e da mulher é reconhecida inclusive pelos organismos internacionais, já que as Nações Unidas, ao elaborarem a Agenda 2030, estabeleceram que um dos objetivos de desenvolvimento sustentável é a eliminação da desigualdade entre os gêneros, reconhecendo, também, a importância do papel feminino para as ações sustentáveis.

O movimento feminista precisa incorporar a questão decolonial e a questão da sustentabilidade, mesmo que não na perspectiva do feminismo ecológico hoje estabelecido, para buscar conjugar a diversidade do sujeito mulher, afastando a universalização impossível, com a necessidade de se trabalhar em prol da sobrevivência do planeta Terra. Sem essa reflexão do movimento feminista, a colonialidade que continuará se abatendo sobre a questão feminina nos países ameríndios também continuará a prejudicar as práticas sustentáveis que possam ser desenvolvidas nessas regiões.

\section{REFERÊNCIAS}

ARENDT, Hanna. A condição humana. 10. ed. Rio de Janeiro: Forense Universitária, 2007.

BEAUVOIR, Simone de. O segundo sexo. Versão digital. 2.ed. Rio de Janeiro: Nova Fronteira, 2009.

BIDASECA, Karina. Experiencias del feminismo contra-hegemónico en America Latina.

Revista Lutas Sociais, N. 27. São Paulo, 2011, pp. 200-203.

Perturbando el texto colonial. Buenos Aires: Editora SB, 2010.

CHAUÍ, Marilena. O que é ideologia. São Paulo: Brasiliense, 1981.

DUSSEL, Enrique. Europa, modernidade e Eurocentrismo. In LANDER, Edgardo (org.). A colonialidade do saber: eurocentrismo e ciências sociais - Perspectivas latino-americanas. Buenos Aires: CLACSO, 2005. Disponível em http://biblioteca.clacso.edu.ar/ar/libros/lander/pt/lander.html. 1993.

1492: O encobrimento do outro - a origem do mito da modernidade. Petrópolis - Vozes,

Liberación de la mujer y erotica lationamericana. 4. ed. Bogotá: Editorial Nueva America, 1990. 
GLIGO, Nicolo. Estilos de desarrollo y medio ambiente en América Latina, un cuarto de siglo después. Santiago de Chile: CEPAL, 2006. Disponível em

https://www.cepal.org/es/publicaciones/5658-estilos-desarrollo-medio-ambiente-america-latinaun-cuarto-siglo-despues.

GÓMEZ-QUINTERO, Juan David. La colonialidad del ser y del saber: la mitologización del desarrollo en América Latina. EL AGORA USB, V. 10, N. 1. Janeiro-julho, 2010. pp. 87-105. Disponível em http://www.redalyc.org/articulo.oa?id=407748992005.

GUDYNAS, Eduardo. Concepciones de la naturaleza y desarrollo en America Latina. Persona y Sociedad, V. 13, N. 1. 1999, pp 101-125. Disponível em http://www.flacsoandes.edu.ec/agora/concepciones-de-la-naturaleza-y-desarrollo-en-americalatina.

LANDER, Edgardo. Ciencias sociales: saberes coloniales y eurocéntricos. In LANDER, Edgardo (org). A colonialidade do saber: Eurocentrismo e ciências sociais - perspectivas latino-americanas. São Paulo: CLACSO, 2005. Disponível em http://biblioteca.clacso.edu.ar/clacso/sur-sur/20100624090901/colonialidade.pdf.

LEFF, Enrique. Imaginarios sociales y sustentabilidad. Revista Cultura y Representaciones Sociales, Año 5, N. 09. pp. 42-121. 2010.

Decrecimiento o desconstrución de la economía: hacia um mundo sustentable. Polis, V. 7, N. 21. pp. 81-90. 2008.

LOJO, María Rosa; MIRANDE, María Eduarda; PALERMO, Zulma. De la (des)colonialidad del género. Lugar social de decir. In BIDASECA, Karina (coord.). Genealogías críticas de la colonialidad en America Latina, Africa, Oriente [livro digital]. Buenos Aires: CLACSO, 2016. Disponível em http://biblioteca.clacso.edu.ar/clacso/sursur/20160210113648/genealogias.pdf.

LUGONES, María. Rumo a um feminismo descolonial. Revista Estudos Feministas, V. 22, N. 3. Florianópolis, 2014, pp. 935-952.

MIYAMOTO, Yumi Maria Helena; KROHLING, Aloisio. Dos direitos das mulheres na perspectiva de Jean-Jacques Rousseau, Mary Wollstonecraft e Olympe de Gouges. XXII Encontro Nacional do CONPEDI - História do Direito. Florianópolis: FUNJAB, 2013, pp. 452-467. Disponível em http://www.publicadireito.com.br/publicacao/unicuritiba/livro.php?gt=25.

MORAIS, Maria Lúcia Sabaa Srur. O que dizem os jornais sobre a Biodiversidade na Amazônia no início do século XXI. VI Congresso Brasileiro de Ciências da Comunicação da Região Norte - Belém - PA. 20-22 jun. 2007. Disponível em http://www.intercom.org.br/papers/regionais/norte2007/resumos/R0089-1.pdf. Acesso em 26 mar. 2018.

NOMURA, Leandro. Mulheres são face oculta do trabalho forçado na moda, dizem especialistas. Folha de São Paulo, publicado em 14 out. 2017. Disponível em 
http://www1.folha.uol.com.br/empreendedorsocial/2017/10/1926291-mulheres-sao-face-ocultado-trabalho-forcado-na-moda-dizem-especialistas.shtml. Acesso em 26 mar. 2018;

JUSTIFICANDO. Mulher de 68 anos é resgatada de situação análoga à escravidão em MG. Carta Capital, publicado em 13 jul. 2017. Disponível em http://justificando.cartacapital.com.br/2017/07/13/mulher-de-68-anos-e-resgatada-em-situacaoanaloga-escravidao-em-mg/. Acesso em 26 mar. 2018.

OKIN, Susan. Moller. Women in western political though. Princeton: Princeton University Press, 2013.

Gênero, o público e o privado. Estudos Feministas. V. 16. N. 02. Florianópolis, mai/ago 2008. Pp. 305-332.

O multiculturalismo é ruim para as mulheres? Revista Brasileira de Ciência Política. N. 04. Brasília, jul/dez 2010. Pp. 355-374.

ONU BRASIL. ONU lança Relatório Global sobre o Tráfico de Pessoas em evento em Brasília com Ivete Sangalo. Disponível em https://nacoesunidas.org/onu-lanca-relatorio-globalsobre-o-trafico-de-pessoas-em-evento-em-brasilia-com-ivete-sangalo/. Acesso em 26 mar. 2018.

ONU MULHERES. Sistema ONU no Brasil divulga nota sobre portaria do trabalho escravo. Publicado em 20 out. 2017. Disponível em http://www.onumulheres.org.br/noticias/sistema-onu-no-brasil-divulga-nota-sobre-portaria-dotrabalho-escravo/. Acesso em 26 mar. 2018.

PULEO, Alicia. Feminismo y ecologia. Mujeres en Red - El periódico feminista. Disponível em http://www.mujeresenred.net/spip.php?article2060. Acesso em 27 abr. 2018.

REDETV. Turismo sexual e tráfico de mulheres caminham lado a lado no Rio de Janeiro. Publicado em 01 out. 2015. Disponível em http://www.redetv.uol.com.br/jornalismo/documentoverdade/videos/ultimos-programas/turismosexual-e-trafico-de-mulheres-caminham-lado-a-lado-no-rio-de-janeiro. Acesso em 26 mar. 2018

REIS, Thiago. Cresce o número de mulheres exploradas em regime análogo à escravidão. Agência Patrícia Galvão, publicado em 11 jun. 2015. Disponível em http://agenciapatriciagalvao.org.br/racismo_/cresce-numero-de-mulheres-exploradas-em-regimeanalogo-a-escravidao/. Acesso em 26 mar. 2018.

RODRÍGUEZ, Marta Pascual; LÓPEZ, Yayo Herrero. Ecofeminismo, una propuesta para repensar el presente y reconstruir el futuro. Boletín ECOS, N. 10. Jan-Mar, 2010. Disponível em http://www.fuhem.es/media/ecosocial/file/Boletin\%20ECOS/ECOS\%20CDV/Boletin_10/ecofe minismo_propuesta_repensar_presente.pdf.

RUETHER, Rosemary Radford. Ecofeminismo: mulheres do primeiro e do terceiro mundo. Estudos Teológicos, V. 36, N. 2. São Leopoldo, 1996, pp. 129-139.

SCOTT, Joan. Gênero: uma categoria útil de análise histórica. Revista Educação \& Realidade, V. 20, N. 2. Jul-dez, 1995, pp. 71-99. 
SEGATO, Rita Laura. Género y colonialidad: en busca de claves de lectura y de un vocabulario estratégico descolonial. In BIDASECA, Karina; VASQUEZ LABA, Vanessa (orgs).

Feminismos y poscolonialidad: descolonizando el feminismo desde y en America Latina. Buenos Aires: Editora Godot, 2011.

SHIVA, Vandana. La mirada del ecofeminismo. Polis, V. 3, N. 9. Santiago, 2004. Disponível em http://www.redalyc.org/articulo.oa.

SORJ, B. O feminino com metáfora da natureza. Revista Estudos Feministas, V. 0, N. 0, 1992, pp. 143-150. Disponível em https://periodicos.ufsc.br/index.php/ref/article/view/15806/14299.

SUNKEL, Osvaldo. Introducción: La interacción entre los estilos de desarrollo y el medio ambiente en América Latina. In SUNKEL, O.; GLIGO, N. Estilos de desarrollo y medio ambiente en la America Latina. Cidade do México: Fondo de Cultura Economica, 1980.

WARREN, Karren. Feminismo ecologista. In SHIVA, Vandanda; MIES, María. El ecofeminismo. Expoentes y posturas críticas. Disponível em

http://www.flacsoandes.edu.ec/biblio/catalog/resGet.php?resId=7495 